\title{
Getting Your Message Across to Your Users
}

\author{
Clarisse Sieckenius de Souza \\ Departamento de Informática, PUC-Rio \\ Rua Marquês de São Vicente 225, RDC sala 501 \\ 22451-900 - Rio de Janeiro, RJ \\ clarissedinf.puc-rio.br \\ http://www-di.inf.puc-rio.br/ clarisse/
}

\begin{abstract}
Most models, theories and perspectives in human-computer interaction focus on users communicating with systems. The very name of our discipline illustrates how pervasive is the idea that users and systems are the only relevant parties involved in the process we want to design or investigate. For over a decade, the Semiotic Engineering Research Group (SERG) has elaborated an alternative account of HCI. In it, what we traditionally call humancomputer interaction is characterized as a particular instance of a more general process of computer-mediated human communication.

Semiotic Engineering views HCI as a case of designer-to-user metacommunication, or communication about how to communicate (with/through the system), when and what for. The designer's metacommunication message conveyed by means of a wide range of communicative exchanges between the users and the system. The system represents designers at interaction time, and each turn of communicative exchange adds a significant piece of knowledge and experience to what eventually becomes the user's interpretation of the designer's message. Thus the metacommunication process is achieved.

In this talk I will provide various examples of designer-to-user metacommunication, and discuss some of the main implications of bringing designers onto the stage where human-computer interaction takes place. I will place a special emphasis on how this alternative perspective encourages designers to express certain values, beliefs and expectations regarding the interactive artifacts they produce, compared with what is enabled and encouraged by more traditional views of HCI. Given the theme of INTERACT 2007, I will illustrate the differences with systems that clearly demand, and encode, an attitude of social responsibility from their designers and developers.

I will wrap up the talk with some final considerations about the cultural roots of Semiotic Engineering, and a conjecture that HCI theories developed outside North America and Europe will reflect their proponents' concern and engagement with remarkably different social and cultural backgrounds. Perhaps, our international community's investment in encouraging the development of such theories will foster progress of our discipline in some innovative directions.
\end{abstract}

Short Bio. Clarisse Sieckenius de Souza graduated as a Translator and Conference Interpreter from PUC-Rio, where she also obtained an M.A. in Portuguese and a Ph.D. in Computational Linguistics. In 1988 she joined the Informatics Department at PUC-Rio, where she started the Human-Computer Interaction (HCI) area. 
Clarisse was the first Brazilian Representative in IFIP's TC13 (the Technical Committee for Human-Computer Interaction). She created the Brazilian Computing Society's Special Interest Group in HCI and coordinated the first of a now successful series of Brazilian Conferences on Human Factors in Computing (the IHC series). In 1996 she founded SERG (the Semiotic Engineering Research Group), which she headed till 2003. Among the 13 M.Sc. and 16 Ph.D. students that she has (co-)supervised, more than a half are faculty in various Brazilian universities, and nearly one third work in the industry.

Along with Alfredo Sánchez (UDLA - Mexico), Clarisse was General Co-Chair of CLIHC2003 - the first Latin American Conference on HCI (Rio de Janeiro, August 17 to 20, 2003). She is also the author of The semiotic engineering of human-computer interaction, published by The MIT Press in 2005. The book presents a full-blown semiotic theory of HCI that was completely and independently developed by SERG, in Brazil. 